
Solutions"

IEEE IECON Industrial Electronics Conference, pp. 1466-1472, Dallas Texas USA, Oct. 2014.

http://ieeexplore.ieee.org/xpl/articleDetails.jsp?tp=\&arnumber=7048695

ISBN: 978-1-4799-4032-5

ISSN: $1553-572 \mathrm{X}$

DOI: 10.1109/IECON.2014.7048695

This material is posted here with permission of the IEEE. Such permission of the IEEE does not in any way imply IEEE endorsement of any of Group of Energy and Power Electronics, University of Minho, products or services. Internal or personal use of this material is permitted. However, permission to reprint/republish this material for advertising or promotional purposes or for creating new collective works for resale or redistribution must be obtained from the IEEE by writing to pubs-permissions@ieee.org. By choosing to view this document, you agree to all provisions of the copyright laws protecting it.

(C) 2014 IEEE 
Delfim Pedrosa, Jorge Carvalho, Henrique Gonçalves, Vítor Monteiro, Aparício Fernandes, João L. Afonso, "Field Oriented Control of an Axial Flux Permanent Magnet Synchronous Motor for Traction Solutions", IEEE IECON Industrial Electronics Conference, pp. 1466-1472, Dallas Texas USA, Oct. 2014, DOI: 10.1109/IECON.2014.7048695.

\title{
Field Oriented Control of an Axial Flux Permanent Magnet Synchronous Motor for Traction Solutions
}

\author{
Delfim Pedrosa, Jorge Carvalho, Henrique Gonçalves, Vítor Monteiro, Aparício Fernandes, João L. Afonso \\ ALGORITMI Research Centre - University of Minho \\ Guimarães, Portugal \\ \{delfim.pedrosa | jorge.carvalho | henrique.goncalves | vitor.monteiro | aparicio.fernandes | joao.l.afonso\}@algoritmi.uminho.pt
}

\begin{abstract}
Electric Vehicles (EVs) are increasingly used nowadays, and different powertrain solutions can be adopted. This paper describes the control system of an axial flux Permanent Magnet Synchronous Motor (PMSM) for EVs powertrain. It is described the implemented Field Oriented Control (FOC) algorithm and the Space Vector Modulation (SVM) technique. Also, the mathematical model of the PMSM is presented. Both, simulation and experimental, results with different types of mechanical load are presented. The experimental results were obtained using a laboratory test bench. The obtained results are discussed.
\end{abstract}

Keywords-Axial Flux Permanent Magnet Synchronous Motor; Field Oriented Control; Space Vector Modulation; Electric Vehicles.

\section{INTRODUCTION}

The replacement of non-renewable energy resources (such as fossil fuels) by more sustainable energy sources is of paramount importance. The general perception of this need is increasing the use of renewable energy resources. It is also known that most of the global energy consumption is used in mobility purposes, and therefore new mobility solutions are being proposed. Electric Vehicles (EVs) are less pollutant and more efficient than vehicles with combustion engines, hence its sales have been growing on vehicle's market [1], [2].

Several types of electric motors can be used in the powertrain of EVs. Nowadays, Permanent Magnet Synchronous Motors (PMSM) are the most used, since they have some advantages over other motors [3], [4], namely:

- High efficiency;

- High power density;

- Reduced rotor losses, the rotor uses magnets;

- Reduced engine size for the same power, in comparison with the internal combustion engine;

- Compact construction;

- Low maintenance costs;

- Wide adaptation to projects specific features due to the variety of available magnets arrangements.

This paper presents the use of a Field Oriented Control (FOC) to drive a PMSM. Several computer simulations and experimental results are also presented. The FOC has the advantages of low ripple and low distortion in the torque's waveforms. It is also compatible with fixed switching frequency pulse width modulation techniques. On the other hand, the FOC has the disadvantage of having a slower response in torque variations, in comparison with some control technics like Direct Torque Control (DTC) [5].

\section{FIELD ORIENTED CONTROL}

The proposed field oriented control is depicted in Fig. 1. In traditional applications the control variable is the speed of the motor. However, for EVs' traction it is more adequate a torque control. So, the speed loop was eliminated and is used a torque reference obtained from the accelerator pedal.

The main advantage of the FOC is the independent control of stator flux and motor torque. To obtain this independency motor's currents are represent in a two axes orthogonal $d-q$ coordinate system $\left(I_{d}\right.$ and $\left.I_{q}\right)$ synchronous with motor's speed. The $I_{d}$ component is responsible to adjust the stator flux, and $I_{q}$ adjusts the torque reference. In order to obtain the maximum torque $I_{\text {dref }}$ is forced to be zero. This condition allows a phase shift between the rotor and the stator flux of $90^{\circ}[6]-[8]$.

The Clarke transform is responsible for transforming a rotational three-phase system in a rotational two dimensional coordinate system, where the two components are $90^{\circ}$ phase shifted. Equation (1) shows the Clark transform of the three-phase currents $i_{A}, i_{B}$, and $i_{C}$.

$$
\left[\begin{array}{l}
i_{\alpha} \\
i_{\beta}
\end{array}\right]=\frac{2}{3}\left[\begin{array}{ccc}
1 & -\frac{1}{2} & -\frac{1}{2} \\
0 & \frac{\sqrt{3}}{2} & -\frac{\sqrt{3}}{2}
\end{array}\right]\left[\begin{array}{l}
i_{A} \\
i_{B} \\
i_{C}
\end{array}\right]
$$

When the system is balanced, the sum of the three currents is zero, and equation (1) can be simplified as shown in equation (2).

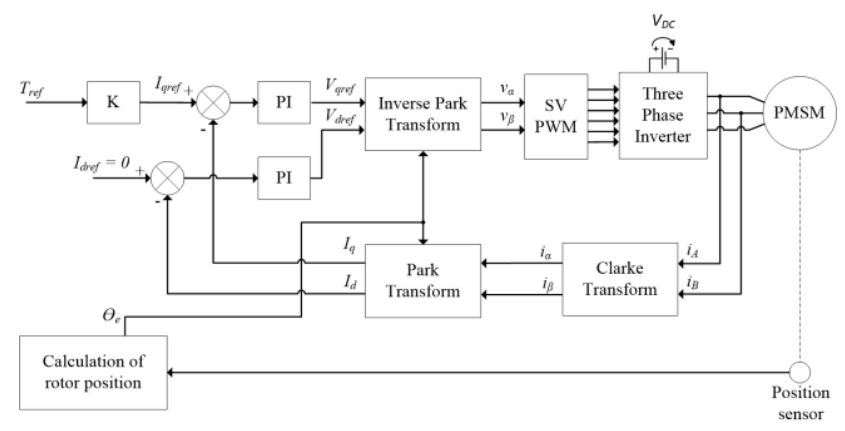

Fig. 1. Field Oriented Control (FOC) block diagram. 


$$
\left[\begin{array}{l}
i_{\alpha} \\
i_{\beta}
\end{array}\right]=\left[\begin{array}{ll}
1 & 0 \\
\frac{1}{\sqrt{3}} & \frac{2}{\sqrt{3}}
\end{array}\right]\left[\begin{array}{l}
i_{A} \\
i_{B}
\end{array}\right]
$$

The Park transform converts a rotational system in a stationary system. Where the inputs are the $i_{\alpha}$ and $i_{\beta}$, obtained from the Clake transform. The Park transform is described by equation (3).

$$
\left[\begin{array}{l}
I_{d} \\
I_{q}
\end{array}\right]=\left[\begin{array}{cc}
\cos \theta_{e} & \operatorname{sen} \theta_{e} \\
-\operatorname{sen} \theta_{e} & \cos \theta_{e}
\end{array}\right]\left[\begin{array}{l}
i_{\alpha} \\
i_{\beta}
\end{array}\right]
$$

Where $\theta_{e}$ is the electrical angle of the motor.

The inverse Park transform is used to convert a stationary system in a rotational system. This inverse transform is used to convert the voltage references for the SVPWM modulation, as shown in equation (4).

$$
\left[\begin{array}{l}
v_{\alpha} \\
v_{\beta}
\end{array}\right]=\left[\begin{array}{cc}
\cos \theta_{e} & -\operatorname{sen} \theta_{e} \\
\operatorname{sen} \theta_{e} & \cos \theta_{e}
\end{array}\right]\left[\begin{array}{l}
V_{d} \\
V_{q}
\end{array}\right]
$$

\section{Space Vector Modulation}

As it can be seen in Fig. 1 the control algorithm (FOC) produces two reference voltages $\left(v_{\alpha}\right.$ and $\left.v_{\beta}\right)$. This two voltage references are the two components in the $\alpha-\beta$ plan of the reference voltage vector $\left(V_{r e f}\right)$, which defines the voltages that should be applied to the motor. To translate the reference voltage in gate pulses for the inverter semiconductors different pulse width modulation techniques can be used [9]. Knowing that the reference voltage is a vector, and considering the high performance of the space vector modulation technique, it was the natural choice.

In Fig. 2 is depicted the vector $V_{\text {ref }}$ in the $\alpha-\beta$ plan.

With the conditions enumerated in equations (5) and (6) it is possible to determine the sector where $V_{\text {ref }}$ is placed, as shown in Table I.

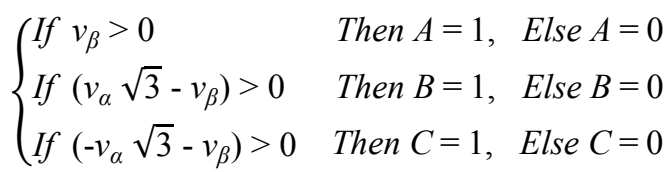

$$
\begin{aligned}
& N=A+2 B+4 C
\end{aligned}
$$

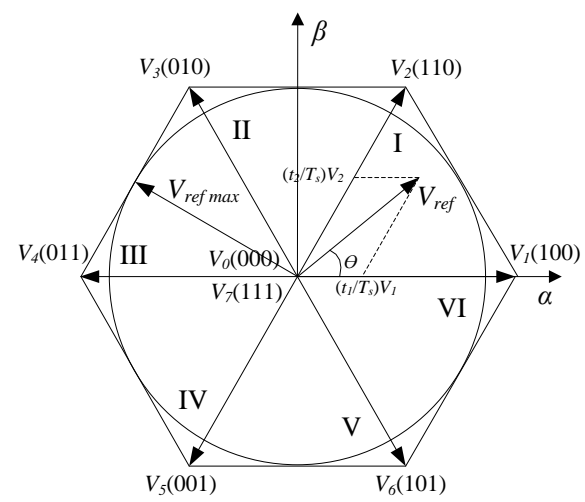

Fig. 2. $V_{\text {ref }}$ location in $\alpha-\beta$ plan.
TABLE I. SECTORS OF $V_{R E F}$

\begin{tabular}{|c|c|c|c|c|c|c|}
\hline $\mathbf{N}$ & $\mathbf{1}$ & $\mathbf{2}$ & $\mathbf{3}$ & $\mathbf{4}$ & $\mathbf{5}$ & $\mathbf{6}$ \\
\hline Sector & II & VI & I & IV & III & V \\
\hline
\end{tabular}

With equation (7) the auxiliary variables $(X, Y$, and $Z)$ are determined. Using Table II the on-duration $\left(t_{1}\right.$ and $\left.t_{2}\right)$ of the switching state vectors are obtained.

$$
\left\{\begin{array}{l}
X=\frac{T_{S} v_{\beta} \sqrt{3}}{V_{C C}} \\
Y=\frac{T_{S}\left(v_{\beta} \sqrt{3}+3 v_{\alpha}\right)}{2 V_{C C}} \\
Z=\frac{T_{S}\left(v_{\beta} \sqrt{3}+3 v_{\alpha}\right)}{2 V_{C C}}
\end{array}\right.
$$

Where $T_{S}$ is the switching period and $V_{c c}$ is the DC-link voltage.

If the condition $t_{1}+t_{2} \leq T_{S}$ is not verified the value of $t_{1}$ and $t_{2}$ needs to be adjusted according to equation (8).

$$
\left\{\begin{array}{l}
t_{1}=\frac{\left(t_{1} T_{S}\right)}{t_{1}+t_{2}} \\
t_{2}=\frac{\left(t_{2} T_{S}\right)}{t_{1}+t_{2}}
\end{array}\right.
$$

With the values of $t_{1}$ and $t_{2}$ the three necessary duty cycles can be calculated using equation (9).

$$
\left\{\begin{array}{l}
t_{a O N}=\frac{\left(T_{S}-t_{1}-t_{2}\right)}{4} \\
t_{b O N}=t_{a O N}+\frac{t_{1}}{2} \\
t_{c O N}=t_{b O N}+\frac{t_{1}}{2}
\end{array}\right.
$$

Finally the duty cycles will be assigned to the right motor phase reference $\left(t_{a}, t_{b}\right.$ and $\left.t_{c}\right)$ according to Table III.

\section{MATHEMATICAl MOdEL OF THE PMSM}

The PMSM was modeled using the $d-q$ axis mathematical model. Therefore, the main equations of the motor are expressed under a $d-q$ coordinate system [10].

The voltage and flux linkage can be written as follows:

TABLE II. ON-DURATION $t_{l}$ AND $t_{2}$ OF THE SWITCHING STATE VECTORS

\begin{tabular}{|c|c|c|c|c|c|c|}
\hline Setor & I & II & III & IV & V & VI \\
\hline $\boldsymbol{t}_{\mathbf{1}}$ & $-Z$ & $Z$ & $X$ & $-X$ & $-Y$ & $Y$ \\
\hline $\boldsymbol{t}_{\mathbf{2}}$ & $X$ & $Y$ & $-Y$ & $Z$ & $-Z$ & $-X$ \\
\hline
\end{tabular}

TABLE III. VALUES OF MOTOR PHASE DUTY CYCLES $t_{a}, t_{b}$ AND $t_{c}$

\begin{tabular}{|c|c|c|c|c|c|c|}
\hline Sector & I & II & III & IV & V & VI \\
\hline $\boldsymbol{t}_{\boldsymbol{a}}$ & $t_{a O N}$ & $t_{b O N}$ & $t_{c O N}$ & $t_{c O N}$ & $t_{b O N}$ & $t_{a O N}$ \\
\hline $\boldsymbol{t}_{\boldsymbol{b}}$ & $t_{b O N}$ & $t_{a O N}$ & $t_{a O N}$ & $t_{b O N}$ & $t_{c O N}$ & $t_{c O N}$ \\
\hline $\boldsymbol{t}_{\boldsymbol{c}}$ & $t_{c O N}$ & $t_{c O N}$ & $t_{b O N}$ & $t_{a O N}$ & $t_{a O N}$ & $t_{b O N}$ \\
\hline
\end{tabular}




$$
\begin{aligned}
& \left\{\begin{array}{l}
V_{d}=R_{s} I_{d}+p \psi_{d}-\omega_{e} \psi_{q} \\
V_{q}=R_{s} I_{q}+p \psi_{q}+\omega_{e} \psi_{d}
\end{array}\right. \\
& \left\{\begin{array}{l}
\psi_{d}=L_{d} I_{d}+\psi_{r} \\
\psi_{q}=L_{q} I_{q}
\end{array}\right.
\end{aligned}
$$

Where $R_{s}$ is the armature resistance, $I_{d}$ and $I_{q}$ are the stator $d$ - $q$ axis currents, $p$ is the pole-pair number, $\omega_{e}$ is the electrical angular speed, $L_{d}$ and $L_{q}$ are the $d-q$ axis inductances, and $\psi_{r}$ is the permanent magnets flux linkage.

The torque is defined by equation (12).

$$
T_{e}=p\left(I_{q} \psi_{d}-I_{d} \psi_{q}\right)
$$

When $I_{d r e f}$ is zero, equation (12) can be rewritten as equation (13).

$$
T_{e}=p I_{q} \psi_{d}
$$

When it is wanted a speed above motor nominal speed a field weakening control algorithm is used. This can be done by making $I_{d r e f}$ greater than zero. However, the maximum torque that can be generated is reduced, since the condition in equation (14) needs to be guaranteed [6].

$$
I_{s}=\sqrt{I_{d}^{2}+I_{q}^{2}} \leq I_{\text {smax }}
$$

It should be noticed that it is not recommended to create fluxes in opposition to the natural flux produced by the permanent magnets during long periods of time. This condition can lead to demagnetization of the permanent magnets, reducing the produced torque, and causing excessive overheating of the motor.

\section{SiMUlation RESUlTS}

Many times it is difficulty of obtaining the necessary motor characteristics from the manufactures. Therefore, a set of experimental tests need to be done in order to obtain these characteristics [11].Table IV presents the main characteristics of the PMSM that were used in the computer simulations and in the experimental results, which were obtained from the manufacturer and from experimental tests.

TABLE IV. CHARACTERISTICS OF THE PMSM

\begin{tabular}{|c|c|c|}
\hline Characteristics & Value & Unit \\
\hline Nominal Power $P_{n}$ & 30 & $\mathrm{~kW}$ \\
\hline Speed $\omega$ & 6000 & $\mathrm{rpm}$ \\
\hline Nominal Voltage $V_{n}$ & 187 & $\mathrm{~V}$ \\
\hline Nominal Current $I_{n}$ & 113.5 & $\mathrm{~A}$ \\
\hline Torque $T$ & 47.7 & $\mathrm{Nm}$ \\
\hline Number of Poles $p$ & 8 & - \\
\hline Nominal Frequency $f$ & 400 & $\mathrm{~Hz}$ \\
\hline Stator Resistance $R_{s}$ & 19.35 & $\mathrm{~m} \Omega$ \\
\hline Inertia $J$ & 5.86 & $\mathrm{mkgm}$ \\
\hline$d$-axis Stator Inductance $L_{d}$ & 100 & $\mu \mathrm{H}$ \\
\hline$q$-axis Stator Inductance $L_{q}$ & 160 & $\mu \mathrm{H}$ \\
\hline Voltage constant $k_{e}$ & 42.1 & $\mathrm{~V} / 1000 \mathrm{rpm}$ \\
\hline
\end{tabular}

\section{A. No-Load Simulations}

The first simulations were performed without using a mechanical load, i.e., with $0 \mathrm{Nm}$ resistant torque. To overcome the motor's inertia, during the startup of the PMSM was applied a reference torque of $7 \mathrm{Nm}$. Once reached the stationary state the torque reference is set to zero.

Fig. 3 shows the waveforms of the torque reference and the torque produced by the PMSM, without mechanical load. It is possible to see that the torque of the PMSM follows the torque reference just up to certain time instant. After this instant the PMSM torque decreases to near $2.5 \mathrm{Nm}$. This instant corresponds to the end of the transitory regimen, when the angular acceleration of the PMSM begins to decrease up to zero. Consequently, the angular momentum will go to zero, and the produced torque depends only of the frictional forces of the system.

Fig. 4 shows the waveforms of the $I_{q r e f}$ and $I_{q}$. The waveform of $I_{q}$ is similar of the waveform of $T$ as expected, since $T$ is directly proportional to $I_{q}$ current.

The motor speed curve is presented in Fig. 5. It can be seen that the system reacts very quickly, reaching the steady-state in approximately $0.2 \mathrm{~s}$.

In Fig. 6 are shown the motor voltages $\left(v_{A B}, v_{B C}\right.$ and $\left.v_{C A}\right)$ and currents $\left(i_{A}, i_{B}\right.$ and $\left.i_{C}\right)$ when the PMSM operates in steady-state without mechanical load. The RMS value of the voltages is $62.5 \mathrm{~V}$ and the RMS value of the currents is $5.9 \mathrm{~A}$.

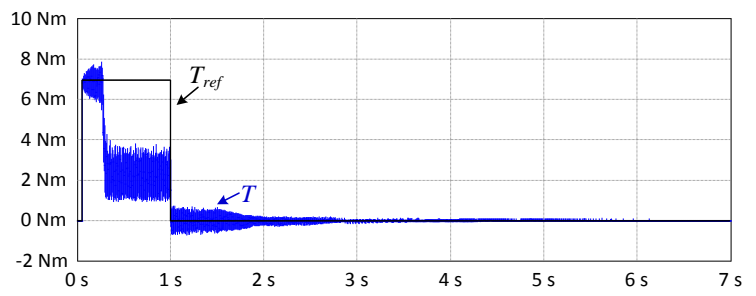

Fig. 3. Torque reference $\left(T_{\text {ref }}\right)$ and PMSM produced torque $(T)$ without mechanical load.

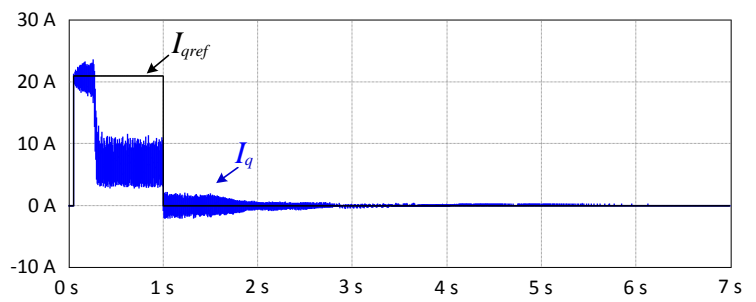

Fig. 4. PMSM no-load stator $d-q$ axis current reference $I_{q r e f}$ and current $I_{q}$.

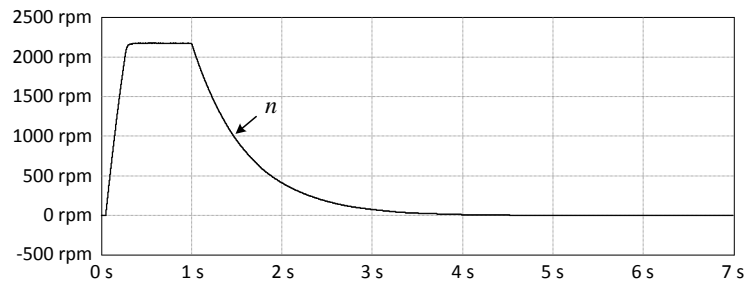

Fig. 5. No-load PMSM speed curve. 


\section{B. Full Load Simulations}

The system was simulated with a mechanical load of 47.7 Nm. In Fig. 7 are shown the waveforms of the reference torque and correspondent motor torque. As it is possible to see the motor torque follows the reference torque up to the instant $t_{1}$. During this time period the produced torque is equal to the sum of the acelleration torque, due to motor enertia, and the risistant mechanical torque of the system. After this instant the produced torque corresponds to the mechanical load torque. When the torque referce $\left(T_{r e f}\right)$ is set to zero, the motor torque $(T)$ follows this reference.

Fig. 8 shows motor speed along the time when operating at full load $(47.7 \mathrm{Nm})$.

Analysing the motor speed at this operating condictionit can be seen that the motor is able to reach the maxímum speed of $2970 \mathrm{rpm}$ in $0.1 \mathrm{~s}$. In Fig. 9 are shown the motor voltages $\left(v_{A B}\right.$, $v_{B C}$ and $\left.v_{C A}\right)$ and currents $\left(i_{A}, i_{B}\right.$ and $\left.i_{C}\right)$ at full load. The RMS value of the voltages is $95.3 \mathrm{~V}$ and the value of the RMS value of the currents is $108.4 \mathrm{~A}$. The currents ripple is caused by the inverter commutation frequency. Comparing this value with the currents ripple shown in Fig. 6 it is significanctly lesser. This is due to the higher RMS currents value. This ripple is still

(a)
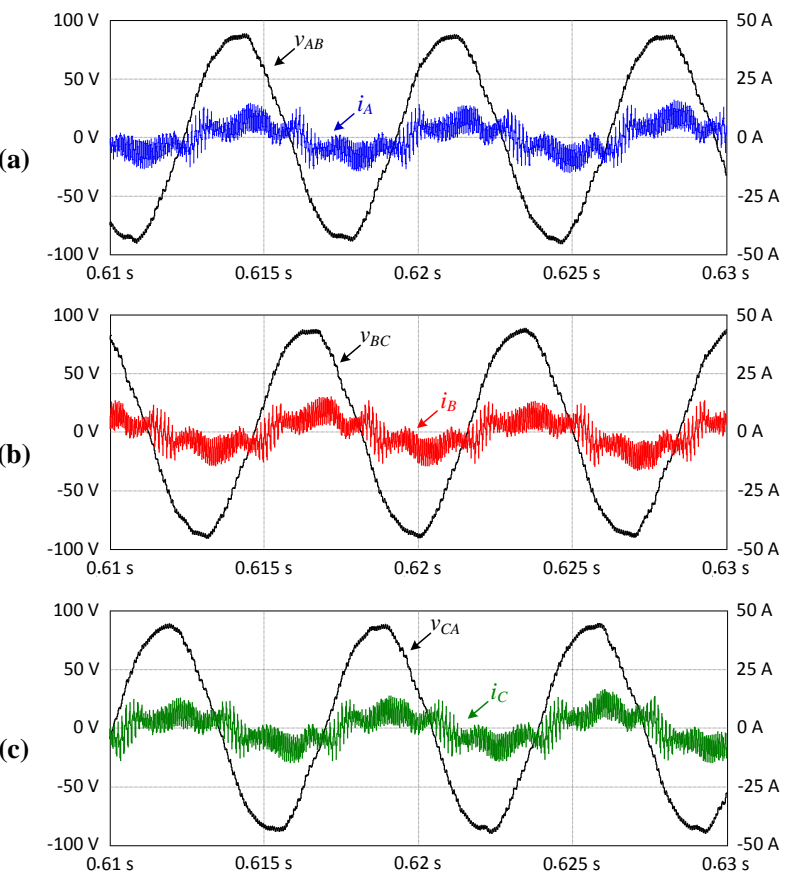

Fig. 6. Voltages and currents of the PMSM with FOC without mechanical load: (a) $v_{A B}$ and $i_{A}$; (b) $v_{B C}$ and $i_{B}$; (c) $v_{C A}$ and $i_{C}$.

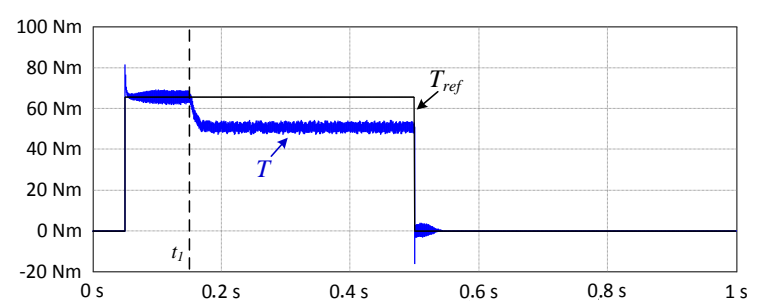

Fig. 7. Torque reference $\left(T_{r e f}\right)$ and PMSM produced torque $(T)$ with full load.

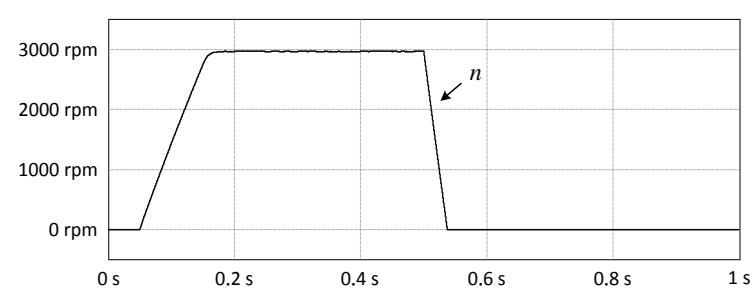

Fig. 8. Full load PMSM speed.

(a)

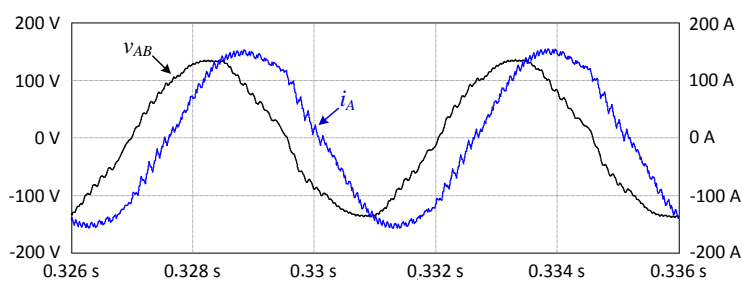

(b)
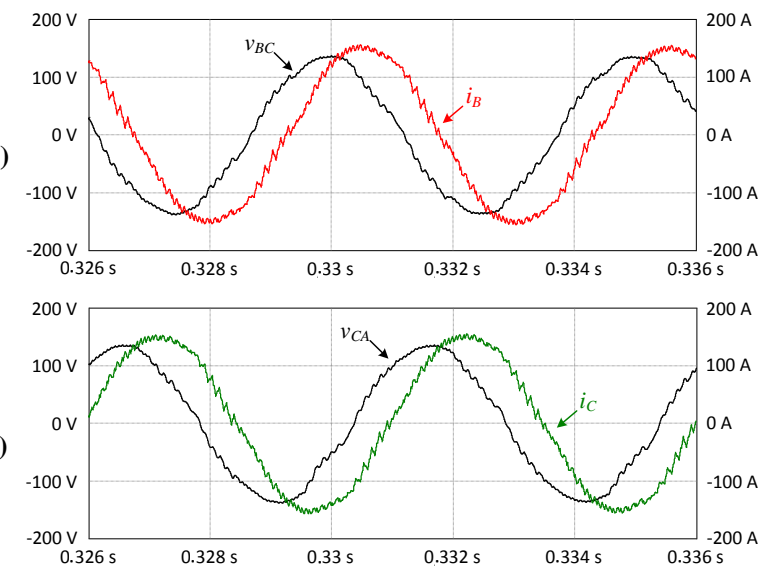

Fig. 9. Voltage and currents of the PMSM with full load: (a) $v_{A B}$ and $i_{A}$; (b) $v_{B C}$ and $i_{B}$; (c) $v_{C A}$ and $i_{C}$.

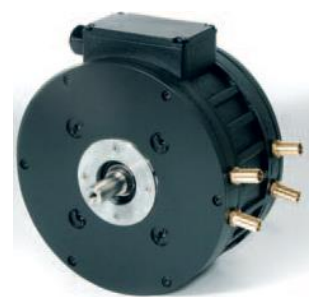

Fig. 10. Axial flux permanent magnet synchronous motor.

significant, but it is justified by the fact that the $200 \mathrm{~Hz}$ motor voltages being sintetized by a comutation frequency of only $8 \mathrm{kHz}$.

\section{EXPERIMENTAL RESULTS}

In Fig. 10 is presented the axial flux permanent magnet synchronous motor that was used to obtain the experimental results.

To drive the motor it was used an inverter laboratorial prototype (Fig. 11). The DC-link of the inverter was fed by battery pack with a nominal voltage of $168 \mathrm{~V}$. The FOC algorithm was implemented in a 32-bit floating-point Digital Signal Controller (DSC). 


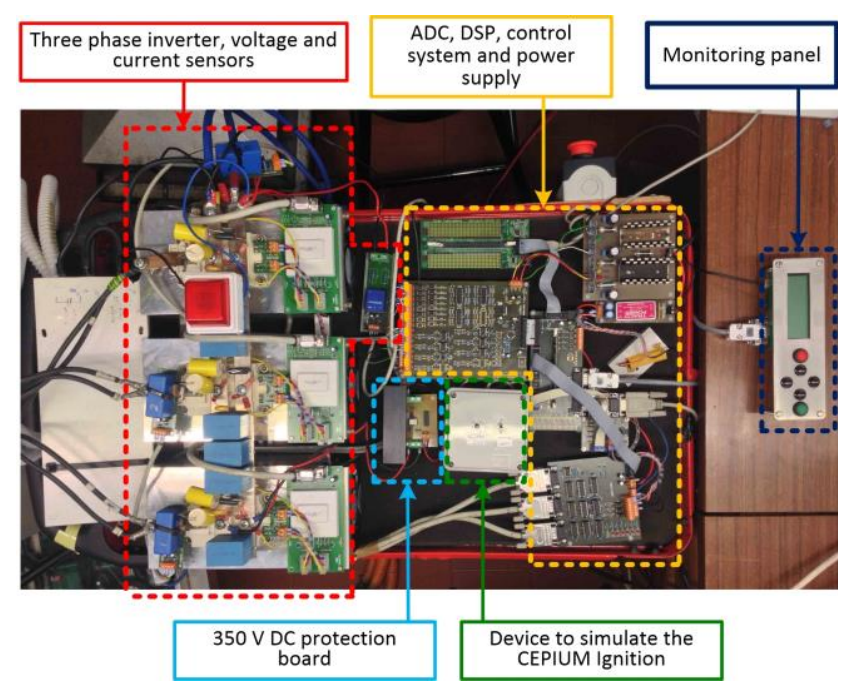

Fig. 11. Controller laboratory prototype.

To assess the behavior of the motor working at different operating conditions it was assembled in a test bench, as shown in Fig. 12.

\section{A. Experimental No-Load Test}

To perform the no-load test the PMSM was put to run without any mechanical load applied in the shaft. In Fig. 13 are

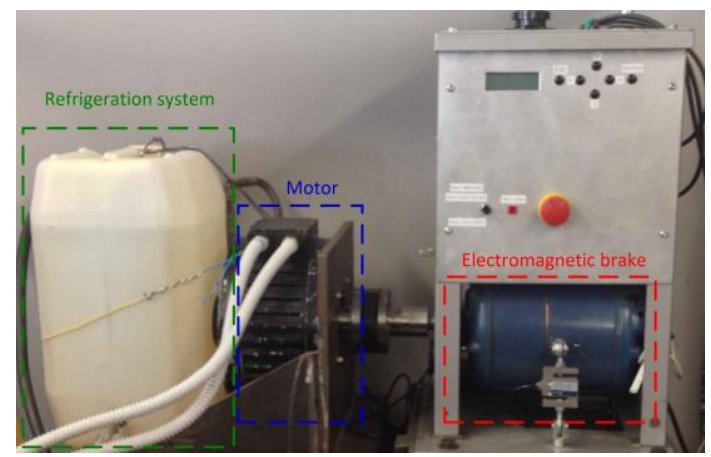

Fig. 12. Test bench with PMSM for test.

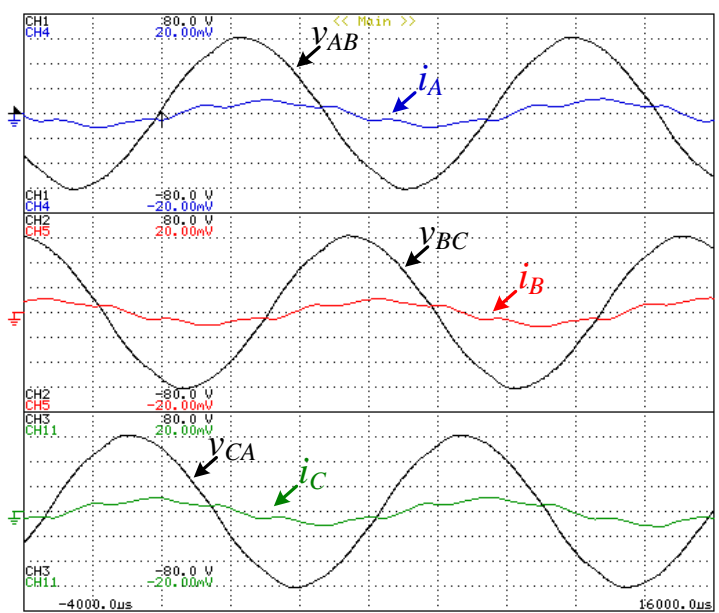

Fig. 13. No-load voltages $\left(v_{A B}, v_{B C}\right.$, and $\left.v_{C A}\right)$ and currents $\left(i_{A}, i_{B}\right.$, and $\left.i_{C}\right)$ in the PMSM. presented the voltages and currents waveforms in the motor. This waveforms were obtained with an Yokogawa DL716 oscilloscope with an input low-pass filter, set with a $500 \mathrm{~Hz}$ cutoff frequency.

The RMS values of the voltages and currents were $42.7 \mathrm{~V}$ and $1.7 \mathrm{~A}$, respectively.

In Fig. 14 are presented the waveforms of the reference current $I_{q r e f}$ and the motor's current $I_{q}$. Four different time instants were depicted. At instant $t_{1}$, the reference $I_{q r e f}$ is changed from 0 to about $21 \mathrm{~A}$. It can be seen that $I_{q}$ follows this reference. At instant $t_{2}$, the value of $I_{q}$ begins to decreases to an average value around $1.5 \mathrm{~A}$. This occurs because the motor finishes accelerating and the acceleration torque becomes zero. At time $t_{3}$, the value of reference $I_{q r e f}$ is set to zero and $I_{q}$ follows the reference to near zero. Between $t_{3}$ and $t_{4}$, the $I_{q}$ ripple decreasing to zero. After $t_{4}$ the PMSM is stopped.

\section{B. Experimental Load Test}

The load test was made using the test bench set to apply a mechanical load of $40 \mathrm{Nm}$. In Fig. 15 are shown the motor voltages and currents. These waveforms were registered using the aforementioned oscilloscope. The RMS value of the voltages and currents were of $66.3 \mathrm{~V}$ and $101.7 \mathrm{~A}$, respectively. When the PMSM runs with a mechanical load the currents waveforms are more sinusoidal.

In Fig. 16 are presented the waveforms of the reference $I_{\text {qref }}$ and the current $I_{q}$ for a mechanical load of $40 \mathrm{Nm}$. Four different time instants are depicted. At instant $t_{1}$ the reference $I_{\text {qref }}$ is changed from 0 to $200 \mathrm{~A}$. The $I_{q}$ follows the reference up to instant $t_{2}$, when it starts to decrease up to $119 \mathrm{~A}$. This occurs because the motor finishes accelerating and the PMSM only needs to produce the mechanical load torque. At $t_{3}$ the reference $I_{\text {qref }}$ is set to zero, and the current $I_{q}$ follows the reference, but with a slight oscillation around zero up to instant $t_{4}$, when the PMSM stops running.

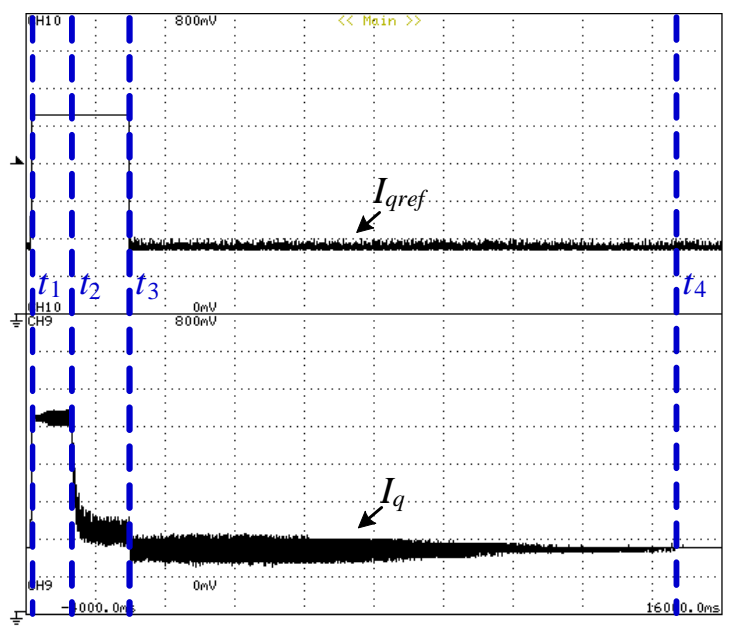

Fig. 14. Stator $d-q$ axis current reference $I_{q r e f}$ and $I_{q}$ current in the PMSM without load. 


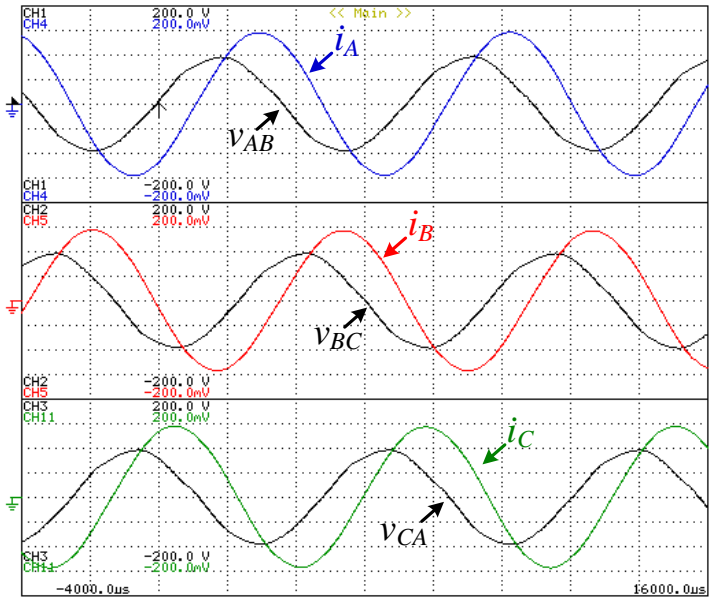

Fig. 15. Voltages and currents of the PMSM with load.

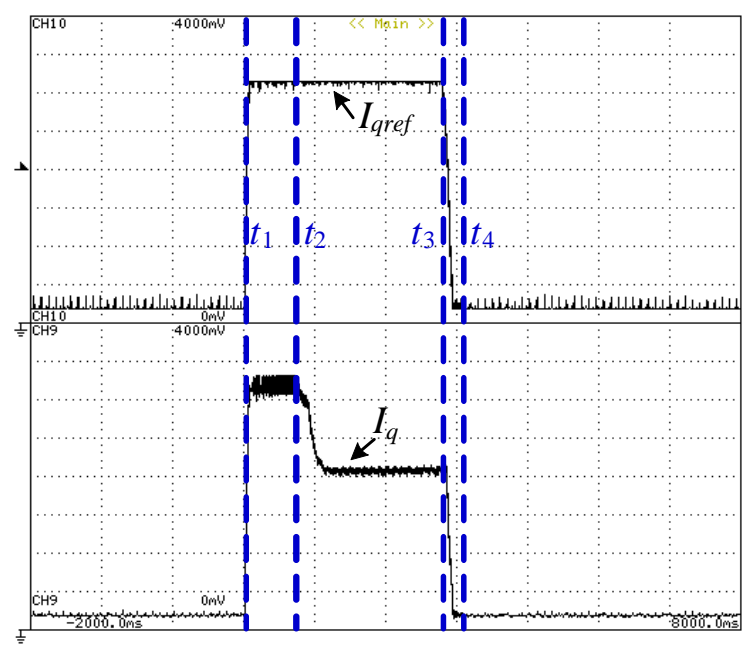

Fig. 16. Stator $d-q$ axis current reference $I_{\text {qref }}$ and $I_{q}$ current in the PMSM with a $40 \mathrm{Nm}$ load.

\section{CONCLUSIONS}

In this paper were presented the simulations and experimental results of the Field Oriented Control (FOC) of an axial flux Permanent Magnet Synchronous Motor (PMSM).

Several tests were performed, both in computer simulations and in a laboratory test bench, in order to obtain experimental results. The experimental results have shown that the FOC presents a fast response to torque reference variations, both with load and no-load torque conditions. The waveforms of currents and voltages presented some ripple due to the low commutation frequency of the three-phase inverter that was used.

The next step of this work will be the integration of the presented system in a car that is being converted to electric vehicle by the Group of Energy and Power Electronics (GEPE) of the University of Minho.

\section{ACKNOWLEDGMENT}

This work has been supported by FCT - Fundação para a Ciência e Tecnologia in the scope of the project: PEstOE/EEI/UI0319/2014.

\section{REFERENCES}

[1] L. L. C. Silva, C. L. Chu, P. T. S. Nascimento, and A. S. Camargo, "Electric vehicles: Struggles in creating a market," Technology Management in the Energy Smart World, pp. 1-13, July 2011.

[2] T. Hofman, and C. H. Dai, "Energy efficiency analysis and comparison of transmission technologies for an electric vehicle," Vehicle Power and Propulsion Conference, pp. 1-6, September 2010.

[3] B. Singh and S. Singh, "State of the Art on Permanent Magnet Brushless DC Motor Drives", Journal of Power Electronics, vol. 9, pp. 1-17, January 2009.

[4] K.T.Chau, C.C.Chan, and Chunhua Liu, "Overview of Permanent Magnet Brushless Drives for Electric and Hybrid Electric Vehicles," IEEE Transactions on Industrial Electronics, vol. 55, pp. 2246-2257, June 2008.

[5] X. T. Garcia, B. Zigmund, A. Terlizzi, R. Pavlanin, and L. Salvatore, "Comparison between FOC and DTC Strategies for Permanent Magnet Synchronous Motors," Advances in Electrical and Electronic Engineering, vol 5, pp. 76-81, 2006.

[6] E. Simon, "Implementation of a Speed Field Oriented Control of 3-phase PMSM Motor using TMS320F240," Texas Instruments, 1999, Available at: http://www.ti.com/lit/an/spra588/spra588.pdf.

[7] D. Rathnakumar, J. LakshmanaPerumal, and T. Srinivasan, "A new software implementation of space vector PWM," IEEE Proc SoutheastCon 2005, pp. 131-136, April 2005.

[8] Y. Li eD. Gerling, "The Comparison of Control Strategies for the Interior PMSM Drive used in the Electric Vehicle," The 25th World Battery, Hybrid and Fuel Cell Electric Vehicle Symposium \& Exhibition, November 2010.

[9] J. Holtz, "Pulsewidth modulation for electronic power conversion," Proceedings of the IEEE, vol.82, no.8, pp.1194,1214, Aug 1994.

[10] X. Wang, Risha Na, and N. Liu, "Simulation of PMSM field-oriented control based on SVPWM," Vehicle Power and Propulsion Conference, pp. 1465-1469, September 2009.

[11] D. Pedrosa, H. Gonçalves, B. Exposto, J. S. Martins, and J. L. Afonso, “A Simplified Methodology for Parameters Measurement of an Axial Flux Permanent Magnet Motor Without Neutral Point," IECON'2012 -38th Annual Conference of the IEEE Industrial Electronics Society, Montreal, Canada, pp. 1637-1642, October 2012.

Delfim Pedrosa ( $\left.\mathrm{S}^{\prime} 10\right)$ was born in Leiria, Portugal on July, 1986. He is a $\mathrm{PhD}$ student at Centro Algoritmi of University of Minho. He received the M.Sc. in Industrial Electronics and Computers Engineering, from the School of Engineering of the University of Minho, in 2010. Since 2010, he is a member of the Group of Energy and Power Electronics (GEPE) at Centro Algoritmi, University of Minho, Guimarães, Portugal. His main researching interests are in Industrial Electronics and Electrical Vehicles.

Jorge Carvalho (S'13) was born in Braga, on August 1990. He finished the Integrated Master degree in Industrial Electronics Engineering from University of Minho, Portugal, in 2013. Now he is an Embedded Software Engineer at Coreworks-sa where his main goal is migration of software to hardware components.

Henrique Gonçalves (S'02-M'10) was born in Valongo, Portugal, in 1975. He received the B.E.E. degree from Instituto Superior de Engenharia do Porto, Porto, Portugal, in 1996 and the B.S., M.Sc., and Ph.D. degrees in electrical and computer engineering from the University of Porto in 1998, 2001, and 2008, respectively. From 1999 to 2006, he was an Assistant Lecturer with the Department of Electrical Engineering, Polytechnic Institute of Bragança, Bragança, Portugal. Since 
2009, he has been an Assistant Researcher with the Group of Energy and Power Electronics (GEPE) at Centro Algoritmi, University of Minho, Guimarães, Portugal. His research interests include the development of power electronics for electric vehicles and power generation using renewable energy.

Vítor Monteiro (S’10) was born in Guimarães, Portugal, on May 1984. He received the M.Sc. in Industrial Electronics and Computers Engineering, from the School of Engineering of the University of Minho, in 2010. Since 2008 he is a member of the Group of Energy and Power Electronics (GEPE) of the Centro Algoritmi, at the University of Minho. Currently he is a $\mathrm{PhD}$ student supported by the doctoral scholarship SFRH/BD/80155/2011 granted by the Portuguese FCT agency, and a collaborator of the Centro Algoritmi of the University of Minho. His research interests are related with Power Electronics Converters, Digital Control Techniques, Smart Grids, and Electric Vehicles.

Aparício Fernandes was graduated in Electrical Engineering, Power Systems Option by the Engineering Faculty of University of Lourenço Marques, and Ph.D. by
University of Minho. Currently is Assistant Professor at the University of Minho and Coordinator of Industrial Electronics Group at Algoritmi Research Center.

João Luiz Afonso (M'00) was born in Rio de Janeiro, Brazil, in 1963. He received the B.S. and M.Sc. degrees in Electrical Engineering from the Federal University of Rio de Janeiro in 1986 and 1991, respectively, and the Ph.D. degree in Industrial Electronics from the University of Minho, Guimarães, Portugal, in 2000. Since 1993, he has been with the Department of Industrial Electronics, University of Minho, where he is Associate Professor. He teaches Electrical Machines, Electrical Energy Systems, Complements of Power Electronics, Electrical Power Quality, Active Power Filters and Renewable Energy. He is a researcher with the Group of Energy and Power Electronics (GEPE), and he coordinates the thematic strand of Sustainable and Smart Cities of the Centro Algoritmi. His research interests include: Power Quality, Active Power Filters, Renewable Energy, Electric Vehicles, Energy Efficiency, Energy Storage Systems, Smart Grids and Smart Cities. 